\title{
Improving women's practices for reducing the severity of menopausal symptoms
}

\author{
Hoda Abedel-Azim Mohamed ${ }^{* 1}$, Sahar Mansour Lamadah² \\ ${ }^{1}$ Obstetric and Gynecological Nursing, Faculty of Nursing, El Minia University, El Minia, Egypt \\ ${ }^{2}$ Obstetric and Gynecological Nursing, Faculty of Nursing, Alexandria University, Alexandria, Egypt
}

Received: September 22, 2015

DOI: $10.5430 /$ jnep.v6n $4 \mathrm{p} 72$
Accepted: December 8, $2015 \quad$ Online Published: December 20, 2015

URL: http://dx.doi.org/10.5430/jnep.v6n4p72

\begin{abstract}
Background: Menopause is a physiological event in the women's life that can strongly affect quality of life. More than $80 \%$ of women state that physical and psychological symptoms are commonly accompany menopause, with different degrees of severity and affect women's health and wellbeing. The aim of the current study was to improve women's practices for reducing severity level of the menopausal symptoms.

Subjects and methods: The study was conducted in the gynecological department in El-Minia general hospital in Egypt using quasi experimental research design with pre-post assessment on 150 women at 45 years. The data collection tools included an interviewing questioner, knowledge assessment tool, practical assessment tool and Menopause Specific Quality of Life Questionnaire used to assess the severity of menopausal symptoms. The study was achieved through three phases namely assessment, implementation and evaluation. Each menopausal woman was evaluated at the assessment phase, and two months after program implementation.

Results: More than half of the women had unsatisfactory knowledge regarding to menopause, in addition $(69.3 \%, 78 \%, 56 \%$ and $71.3 \%$ ) of women had improper practices for their vasomotor, psychosocial, physical and sexual health complains respectively at pretest. There were statistically significant improvement in the reduction of the severity menopausal symptoms and improve women practice with common menopausal health complains at posttest $(p<.0001)$.

Conclusions: Improving women's practices can be effective in reducing the severity of menopausal symptoms. It is recommended that, health care providers need to play essential role in assessing women's needs and increase women awareness through implementing proper health educational session about the menopausal age and how to dealing with common health complains associated with menopausal age.
\end{abstract}

Key Words: Menopausal age, Menopausal symptoms, Menopause

\section{INTRODUCTION}

Menopausal age is an adaptation process characterized by biological, psychosocial changes and normal physiological process characterized by the permanent termination of menses in women due to reduced ovarian hormones secretion and usually occurring in women in the range of age between 46 and 55 years. ${ }^{[1]}$ During this period, the women experi- ence different symptoms as hot flashes, sweats, diminished memory, insomnia, depression, bone and joint complaints. Duration, severity, and effect of these symptoms differ from woman to woman. Some women have severe symptoms that greatly affect their health, social functioning, and quality of life. ${ }^{[2]}$ Vasomotor symptoms are the most common physical complaint experienced by the women through menopausal

\footnotetext{
*Correspondence: Hoda Abedel-Azim Mohamed; Email: Hoda.azim@yahoo.com; Address: Obstetric and Gynecological Nursing, Faculty of Nursing, El Minia University, El Minia, Egypt.
} 
period. ${ }^{[3,4]}$

Psychological symptoms that associated with menopausal period are fatigue and anxiety. ${ }^{[5]}$ Other menopausal symptoms such as anxiety, fatigue, sleep turbulences, and weight increase can also occur in non-postmenopausal women. ${ }^{[6]}$ In a survey of women who have experienced the menopause, they reported one or more of these symptoms. ${ }^{[3]}$

While the majority of the women experiencing multiple symptoms during menopausal period, the results of different studies still indicate to a gap on whether collections of symptoms regularly occur and its effect on quality of life. ${ }^{[3]}$ Gohar (2009) ${ }^{[7]}$ reported that, most of the menopausal women experienced vasomotor symptoms such as hot flushes and tiredness. Frequency and severity of symptoms can vary according to epidemiological features of the population and the methods used for data collection. ${ }^{[8]}$ The effect of menopausal period on quality of women's lives includes changes in physical health, psychosomatic domains, and personal life. More than $40 \%$ of menopausal women in Sweden experienced vasomotor symptoms until the age of 65 years. ${ }^{\text {[9] }}$

The mean age of the menopausal woman in Egypt is 46 years, which is low, but this age has been increased during the past few years in the western countries, this may be due to various sociocultural attitudes towards the menopausal age in different communities. Around one third of western women had positive attitude toward the menopause period as "a normal physiological process". However, the Egyptian women need to increase their awareness about menopausal age as important stage of their lives. ${ }^{[10]}$

The use of Hormone replacement therapy (HRT) to Changing ovarian hormone levels and hormonal therapy are excellent for preventing hot flushes, vaginal dryness and related vaginal symptoms, and may help to improve sleeping pattern during menopause. ${ }^{[11]}$ Long-term use of HRT also has a benefit in helping to prevent brittle bones (osteoporosis). ${ }^{[11]}$ As a health care provider must give the menopausal women an accurate and up to date information. ${ }^{[12]}$

According to Lowdermilk et al. (2009), ${ }^{[13]}$ there are different methods to decrease the menopausal symptoms such as stop smoking, take calcium and vitamin $\mathrm{D}$, fat intake, control weight, practice simple exercise regularly to reinforce the bones, wear light cotton clothes to decrease hot flushes, practice pelvic flower muscles exercise regularly to strengthening perineal area, use analgesics according to doctor's order, and adopt a stress management program.

Lifestyle modifications should be the first-line approach for women with menopausal symptoms because changing lifestyle is an effective and safe alternative for the manage- ment of menopausal symptoms. ${ }^{[14]}$ So symptomatic women can adopt healthy behaviors to reduce hot flashes and sweats such as maintaining body temperature cool by wearing light clothes, using portable fan , selecting cold fluids and sleeping in cool environment. ${ }^{[15]}$ Active women report fewer hot flashes than inactive women. Other healthy lifestyles such as eat a healthy food, and avoid dietary causes hot flush occurrence such as (spicy and hot foods, caffeine, and alcohol) can help to reduce hot flashes. ${ }^{[15,16]}$ In addition, lubricants and moisturizers are more effective in reducing pain during intercourse for women with moderate vaginal dryness.

\subsection{Significance of the current study}

Menopausal period is a normal physiological process that can affect the women quality of life. Up to $81 \%$ of women report that physical and psychological health complains during menopausal period, with altered degrees in the severity and lifecycle disturbance. ${ }^{[17]}$ The prevalence of menopausal symptoms among Egyptian women is $84 \%$. So increase life expectancy from 54 to 71 years lead to women experiencing menopausal health complains for a long time. Therefore the health care of women during this period requires special care to assess their health needs in order to provide competent care. ${ }^{[18]}$ Promoting good physical and psychological health during menopausal age is important for individuals in later life. ${ }^{[19-21]}$ Thus increasing women's awareness and dealing with their health complains are important to decrease severity of menopausal symptoms.

\subsection{Aim of the current study}

The aim of the current study was to improve women's practices for reducing severity level of the menopausal symptoms.

\subsection{Research questions}

(1) What are the more severe menopausal symptoms reported by women?

(2) In what way the women dealing with the health complains related to menopausal age?

(3) Does improving women's knowledge have an effect on reducing the severity level of menopausal health complains?

(4) Does improving women's knowledge have an effect on improving women's practices toward their health complains associated with menopausal age?

\subsection{Conceptual framework}

The theoretical framework that guided this study was Orem's model that's focuses on each individual has the ability to perform self-care, and are responsible for their health and the health of their dependents. Self-care is "the practice of activities that individuals initiate and perform on their 
own behalf in maintaining life, health, and well-being". According to Cardinal and Stritch (2011), ${ }^{[22]}$ Orem's Self-Care Model describes a structure where in the nurse assists the client, where needed, to maintain an adequate level of selfcare. The degree of nursing care and intervention depends on the degree to which the client is able (or unable) to meet self-care needs. ${ }^{[23]}$

\section{SUBJECTS AND METHODS}

\subsection{Study design and setting}

Quasi experimental research design with pre-post assessment was used in this study that is appropriate for the nature of current research problem and frequently used in nursing researches. The present study was conducted in obstetric and gynecological department and outpatient clinics in El Minia general hospital Minia city in Egypt.

\subsection{Study subjects}

A purposive sample of 150 menopausal women was enrolled in this current study according to the following inclusion criteria: aged 45 years and more, able to read and write and don't take hormonal therapy.

\subsection{Tools used for data collection}

The data collections tools consisted of four tools:

Tool 1: Interviewing questionnaire: This tool developed by the researchers was used to collect data related to demographic characteristics such as age, education level, occupation and menopausal stage.

Tool 2: Knowledge assessment tool: This tool developed by the researcher was used to collect data related to knowledge of women about menopausal age. It consisted of 20 multiple choice questions related to Meaning of menopausal age, beginning, signs and symptoms, health screening test, and hormonal replacement therapy (meaning, types, side effect, and complication).

Scoring system: For each items had two levels of responses as the correct answer for any item was given score of one and incorrect answer or do not know given zero. Total responses for all items was 20 score equal to $(100 \%)$ related to women responses. The scores of each area of knowledge were added and converted into a percent score. Women satisfactory responses were classified as satisfactory knowledge when $\geq$ $50 \%$ from women responses while the responses with lower than $50 \%$ was considered unsatisfactory knowledge.

Tool 3: Practice assessment tool: This tool developed by the researchers was used to assess women's health practices regarding menopausal symptoms through asking questions about how to deal with these menopausal discomfort. It consisted of 20 multiple choice questions.

Scoring system: Each item had 2 levels of responses: proper practice scored one while improper practice scored zero. Total responses of all items was 20 scores and equal to $100 \%$ related to woman responses. The scores of each area of practice were added and converted into a percent score. Women practice with their health problem were classified as proper practice was considered when more than or equal $(50 \%)$ of correct practice while improper practice was considered when less than $(50 \%)$ of correct practice.

Tool 4: Menopause specific quality of life questionnaire: It is a self-administered report questionnaire was adopted from Lewis et al. (2005). ${ }^{[14]}$ to assess the severity of menopausal symptoms. It included 29 statements in 4 main domains: vasomotor (three statements), physical (16 statements) psychosocial (seven statements), and sexual (three statements). One to eight rate score are used for each of the 29 statements, "one point" for women responding "no", indicating (no experience of this symptom in the last month). "two point" for women experiencing the symptom in the last month, but it was not troublesome. While scores from "three" to "eight point" indicate increasing level of troublesome of the symptom experienced by the women. Scoring system of the severities of menopause symptoms as the following, Scores range from 2-4 consider mild symptoms, 5-6 moderate symptoms, while 7-8 consider severe symptoms. Woman was asked if she experienced the menopausal symptoms in the last six months, if the woman response was no, asked the next question and if the woman response was yes she asked to determine the bothered of the symptoms on a 7 point scale ranging from zero equal not at all bothered to 6 very bothered. For analysis score 1 for "No", score 2 for "Yes" through to 8 for "Yes (Very bothered)". Tools used for collection of the data were translated to Arabic languish then tested and confirmed by fluent individuals.

\subsection{Tools validity and reliability}

The current study tools were submitted to three academic nursing experts in the Obstetric Nursing field to test the face and content validity of the tools, necessary modifications were carried out according to the academic nursing experts' judgment on clarity of sentences and the appropriateness of the content. Tools reliability was tested using internal consistency methods (Alpha Cronbach test). Its result was 0.88 which indicates an accepted reliability of the tools.

\subsection{Pilot study}

A pilot study was conducted on 15 (10\%) menopausal women. It was selected from the previously mentioned study setting according to inclusion criteria to assess the current 
study tools for its clarity, validity, applicability and the time required to fill the tools. Necessary modifications of the tools were done according to pilot results to reach the finalized form. The subjects who included in the pilot study were excluded from the total study sample.

\subsection{Procedure}

The study was achieved through three phases namely assessment, implementation, and evaluation. The researchers attended the gynecological department and outpatient clinic of the previous setting two days/week, from 10.00 a.m. to 2.00 p.m. This study started from the beginning of October 2013 to the end of March 2014. The researchers began with introducing themselves and providing clear explanation about the nature, aim and purpose of the current study to the women who met the study criteria. Each woman was informed that sharing in this study is voluntary. Oral approval of women to share in this study was achieved. Collection of the required data was carried out through meeting with participated women. Time spent for each interview ranged from 25 to 30 minutes by using the previously stated tools.

\subsubsection{Assessment phase}

The purpose of this phase was to collect data as well as to identify women needs. Data related to demographic characteristics, experience and severity level of menopausal symptoms were collected. Menopausal stage was determined according to women's report about length of time since their last menstrual period. Menopause transition stage was considered when women report slight change in the length of their last menstrual cycle. While post menopause stage is determined for women who have spent a year or more without menstruation. In addition, women's knowledge regarding the menopausal period were assessed through asking questions.

\subsubsection{Implementation phase}

After orienting the women about the aim of the study, women were informed (oral and written). The intervention was designed based on review of relevant literature and women's needs identified in the pre-test in order to provide competent care. The theoretical part emphasized on improving women's knowledge regarding menopausal age. It includes the following items as explained in the women's handout: identifying meaning of menopausal age, onset of menopausal age, signs and symptoms, health screening test. Also, it enclosed the explanation of hormonal replacement therapy, its meaning, types, side effect, and complication. The intervention also covered different non hormonal measures and proper practices with each menopausal symptoms.

During the practical session, women learn how to deal with their menopausal symptoms such as care of vasomotor symp-

Published by Sciedu Press toms (hot flashes, night sweats) through advising her to reducing the temperature in a room, dressing in layers, and the use of a fan during sleeping can be effective ways to help deal with troublesome hot flashes. More over women who are overweight tend to have more bothersome hot flashes, therefore weight loss can be helpful. Regarding psychosocial symptoms such as (women feeling of dissatisfied with her life, feeling nervous or depressed, poor memory etc.), the researchers advised women to engage in a creative outlet that fosters a sense of achievement, participate in pleasurable activities, and stay connected with their family, community and friends. In addition, the researcher explained to the women how to deal with the physical symptoms such as (pain, tiredness, backache, headache, sleep disturbance, etc.). This symptoms can be reduced by maintaining the bedroom cool to prevent night sweat, perform exercise daily. Nutrition, advice focused on recommendation of diet which excluded items such as (caffeine, spicy foods, and alcohol) and try to choose natural foods rather than supplements.

As well as the technique of abdominal breathing, the researchers instructed the women the following steps:

(1) Lying on a flat surface (floor or bed), take a deep breath through your nose and expand your abdominal muscles.

(2) Slowly exhale and tighten your abdominal muscles for 3 to 5 seconds.

(3) Repeat this for several times.

In addition, teaching the women how to perform kegel exercises properly, the technique of kegel exercises is as the following steps:

(1) Help her to identify the correct pelvic floor muscles by contracting them to stop the flow of urine while sitting on the toilet.

(2) Repeat this contraction several times to become familiar with it.

(3) Start the exercises by emptying the bladder.

(4) Tighten the pelvic floor muscles and hold for $10 \mathrm{sec}-$ onds.

(5) Relax the muscles completely for 10 seconds.

(6) Perform 10 exercises at least three times daily.

(7) Perform exercises in different positions, such as standing, lying, and sitting, and

(8) Keep breathing during exercises. ${ }^{[24]}$

Moreover, ask the women to use a vaginal lotion or lubricant before intercourse to deal with sexual complains such as vaginal dryness, and decrease sexual desire.

In addition, the researchers explained that the changes of their daily lifestyle should reduce both the number and severity of 
menopausal symptoms like hot flashes, night sweating, fatigue, anxiety, sleep disturbances, and weight gain. Through individualized or group educational session, the researchers explained and discussed for each woman how to perform proper practices, Lectures, group discussion, verbal instructions, demonstration and women's re demonstration were used as learning approaches. A helpful handout suitable for women's level of understanding was also prepared by the researchers according to women's needs and was given to them. Reinforcing information was given in classes. The time taken for education session about two hour to present all needed information and practices. It is divided into three parts (first part that around 30 minutes covered theoretical knowledge and second part takes around one hour covered practical session and third part takes around 30 minutes for discussion, asking and answering any question).

At the end of the education session, the researchers explain the importance of follow-up to confirm the improvement of woman's practices and to assess menopausal symptoms severity. Through periodic contacts with the women by telephone calls, the researchers encouraged the women to do proper practices through refreshing the provided knowledge, answering women questions and reminding them the benefits of proper care.

\subsubsection{Evaluation phase}

Two evaluation were done for each women, the first one was at the beginning of the study as a baseline data. Second evaluation was conducted after two month following the education session, the researchers met the women again and collect the data again related to menopausal symptoms severity and women practices (post-test). The same assessment tools were used during the two evaluations.

\subsection{Administrative design and ethical considerations}

The study conducted over a period of 6 months from October 2013 to the end of March 2014. An official letter clarifying the purpose and setting of the study was obtained from the directors of El Minia General Hospital and it was submitted to the directors of Obstetrics and Gynecology departments requesting their approval for data collection to conduct the study. Each women were informed about the significant and aim of the study. Verbal consent to participate in the current study was obtained from each participant women. All women were informed that their participation is voluntary and were knowledgeable about their rights to refuse or withdraw, and about confidentiality of the information obtained and that the collected data would be only used for the purpose of the current study, as well as for their benefit. All data were considered confidential.

\subsection{Statistical analysis}

Statistical Package for Social Sciences (SPSS) version 17.0 was used for quantitative data analysis. Data were presented using descriptive statistics in the form of frequencies and percentages for qualitative variables and means and standard deviations and medians for quantitative variables. Cronbach alpha coefficient was calculated to assess the reliability of the developed tools through their internal consistency. Qualitative variables categorical were compared using chi-square test. Quantitative continuous data were compared using independent simples $T$-Test. A significant $P$-value was considered when $P$ less than .05 and highly significant when $P$-value less than or equal .01.

\section{RESUlts}

Table 1 shows that more than one half of the women $(56.7 \%)$ their age ranged between 45-55 years. As regards the level of education, women who have university education was $20.0 \%$, while $33.3 \%$ had secondary education. In relation to occupation, more than half of the women $(53.3 \%)$ housewives and $46.7 \%$ working women. Figure 1 shows that $38 \%$ of women at post-menopausal stage but remaining $62 \%$ at menopausal transition stage.

Table 1. Percent distribution of the women related to their demographic data $(n=150)$

\begin{tabular}{lll}
\hline Items & No. & \% \\
\hline Age & & \\
$45-55$ & 85 & 56.7 \\
$>55$ & 65 & 43.3 \\
Education level & & \\
$\quad$ Read and write & 30 & 20 \\
Intermediate & 40 & 26.7 \\
Secondary & 50 & 33.3 \\
University & 30 & 20 \\
Occupation & & \\
$\quad$ Work & 70 & 46.7 \\
Housewife & 80 & 53.3 \\
\hline
\end{tabular}

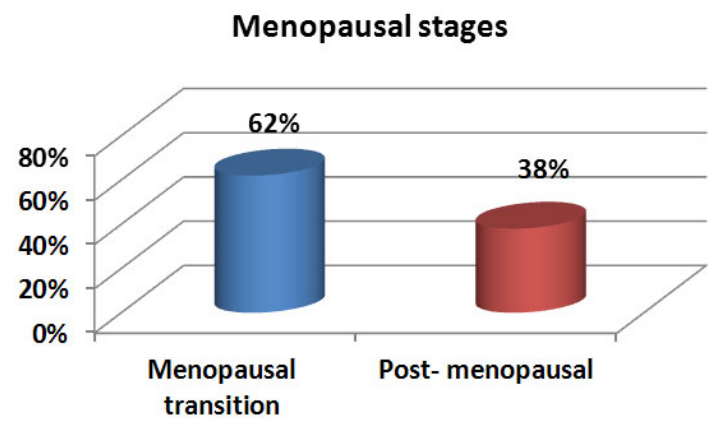

Figure 1. Percent distribution of the women related to menopausal stages $(n=150)$ 
Figure 2 shows the total menopausal symptoms reported by the menopausal women. More than three quarters of women $(78.0 \%$ ) complained from vasomotor symptoms followed by $73.3 \%$ suffered from sexual symptoms, then $72.7 \%$ complained from physical symptoms while $70.0 \%$ had psychosocial complains. As regarding to the severity level of the menopausal symptoms of the women (see Table 2). It can be seen that, the most severe symptoms for vasomotor domain are hot flushes (33.3\%) and night sweats $(25.6 \%)$, while poor memory (38.1\%), unhappy with their life $(30.5 \%)$, and accomplishing less than she used to $(21.9 \%)$ were the most severe symptoms among psychosocial domain, regarding physical domain, the most severe symptoms were, aching of muscles \& joints, weight gain, drying skin, feeling lack of energy and involuntary urination and increased their facial hair $(34.9 \%, 33.9 \%, 33.0 \%, 32.1 \%, 31.2 \%$ and $31.2 \%)$ respectively. Regarding sexual domains $(25.5 \%)$ of women complained of vaginal dryness during intercourse.

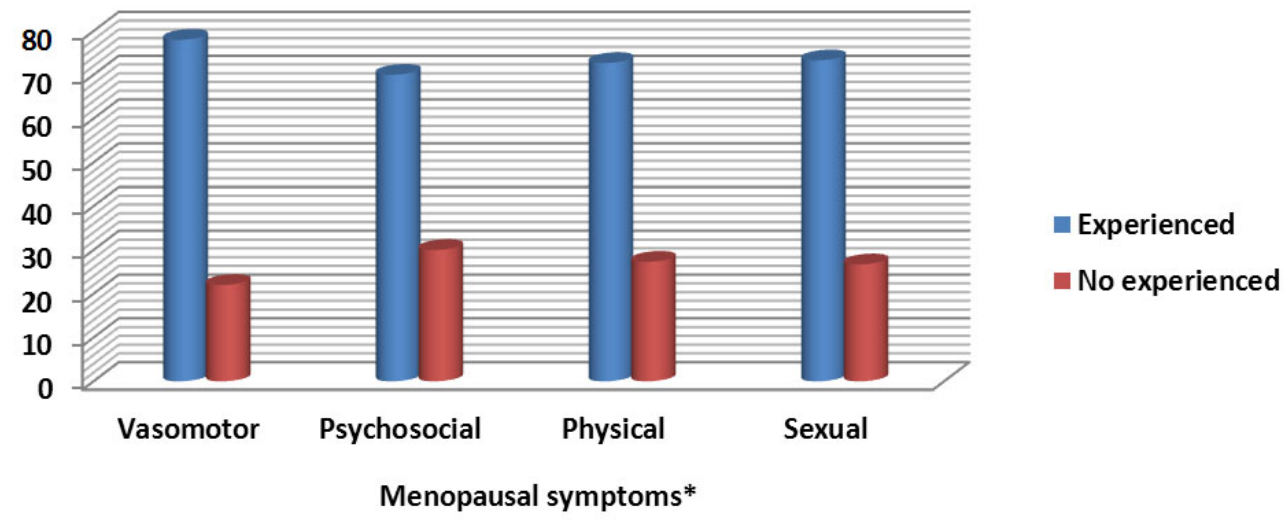

Figure 2. Women distribution by their total menopausal symptoms experiences $(\mathrm{n}=150)$

*Multiple responses

As shown in Table 3, women had unsatisfactory knowledge about the meaning of menopausal age $(64.7 \%)$, onset of menopausal age $(58.7 \%)$, signs and symptoms $(58.7 \%)$ and hormonal replacement therapy (59.3\%). In addition, $64.0 \%$ of women had unsatisfactory knowledge regarding to health screening tests. Regarding to women practices to deal with their common menopausal health complains, Table 4 showed that a considerable percent of women had improper practices for their vasomotor, psychosocial, physical and sexual health complains.

Regarding women's distribution related to the severity level of symptoms pre/post-test. Statistical significant reduction in the severity level of the menopausal symptoms pre and post-test was observed. Vasomotor symptoms decreased from $33.3 \%$ to $23.9 \%$, severity of psychosocial symptoms decreased from $30.5 \%$ to $15.2 \%$, in addition physical symptoms decreased from $30.3 \%$ to $20.2 \%$ and severity of sexual symptoms decreased from $19.1 \%$ to $11.8 \%(P<.0001)$ (see Table 5).

As shown in Table 6, which illustrates women's distribution according to their practices and how to deal with the menopausal health complains pre and posttest. It can be observed that, there was a statistical significant improvement regarding women practice from pre to posttest. The number of women who practice in proper manner with the vaso-

Published by Sciedu Press motor, psychosocial, physical and sexual health complaints improved from $(30.7 \%$ to $76 \%, 22 \%$ to $60 \%, 44 \%$ to $77.3 \%$ and $28.7 \%$ to $70.7 \%$ ) respectively and the difference is statistically significant $(P<.000)$. Table 7 showed the relation between knowledge of the women and practices with their menopausal complaints. It was observed that $84.9 \%$ from woman have proper practices with satisfactory knowledge as compared to $(3.5 \%)$ of them have improper practices $(P=$ $.000)$.

\section{Discussions}

Menopausal age was considered as a transitional period each woman must go through it. The woman response to menopausal age and decreased of estrogen hormone due to lifestyle, education, and dietary habits differ from woman to woman. Promoting the women quality of life is an importance. So, the current study aims to improve women's practices for reducing severity level of the menopausal symptoms. The present study was set to answer the research questions that, identify the more severe menopausal symptoms reported by women, how the women deal with the health complains related to menopausal age, Improving women's knowledge would lead to reduce the severity level of menopausal health complains, with subsequent positive impact on improving their practices with health complains associated with menopausal age. 
Table 2. Distribution of the sample according to severity level of symptoms $(\mathrm{n}=150)$

\begin{tabular}{|c|c|c|c|c|c|c|}
\hline \multirow{2}{*}{ Items* } & \multicolumn{2}{|c|}{ Mild } & \multicolumn{2}{|c|}{ Moderate } & \multicolumn{2}{|c|}{ Severe } \\
\hline & No & $\%$ & No & $\%$ & No & $\%$ \\
\hline \multicolumn{7}{|l|}{ Vasomotor } \\
\hline Hot flush & 51 & 43.6 & 27 & 23.1 & 39 & 33.3 \\
\hline Night sweats & 53 & 45.3 & 34 & 29.1 & 30 & 25.6 \\
\hline Sweating & 56 & 47.9 & 38 & 32.5 & 23 & 19.7 \\
\hline \multicolumn{7}{|l|}{ Psychosocial } \\
\hline Being dissatisfied with my personal life & 52 & 49.5 & 21 & 20 & 32 & 30.5 \\
\hline Feeling nervous & 65 & 61.9 & 21 & 20 & 19 & 18.1 \\
\hline Experiencing poor memory & 42 & 40 & 23 & 21.9 & 40 & 38.1 \\
\hline Accomplishing less than I used to & 37 & 35.2 & 45 & 42.9 & 23 & 21.9 \\
\hline Feeling depressed, down or blue & 57 & 54.3 & 27 & 25.7 & 21 & 20 \\
\hline Being impatient with other people & 59 & 56.2 & 27 & 25.7 & 19 & 18.1 \\
\hline Feelings of wanting to be alone & 50 & 47.6 & 36 & 34.3 & 19 & 18.1 \\
\hline \multicolumn{7}{|l|}{ Physical } \\
\hline Flatulence (wind)or gas pains & 59 & 54.1 & 23 & 21.1 & 27 & 24.8 \\
\hline Aching in muscle \& joints & 46 & 42.2 & 25 & 22.9 & 38 & 34.9 \\
\hline Feel tired & 51 & 46.8 & 28 & 25.7 & 30 & 27.5 \\
\hline Difficulty sleeping & 59 & 54.1 & 17 & 15.6 & 33 & 30.3 \\
\hline Backache and neck Ache or headache & 70 & 64.2 & 16 & 14.7 & 23 & 21.1 \\
\hline Decrease in physical Strength & 61 & 56 & 27 & 24.8 & 21 & 19.3 \\
\hline Decrease in stamina & 53 & 48.6 & 31 & 28.4 & 25 & 22.9 \\
\hline Feel lack of energy & 57 & 52.3 & 16 & 14.7 & 36 & 33 \\
\hline Dry skin & 51 & 46.8 & 23 & 21.1 & 35 & 32.1 \\
\hline Weight gain & 42 & 38.5 & 30 & 27.5 & 37 & 33.9 \\
\hline Increased facial hair & 55 & 50.5 & 20 & 18.3 & 34 & 31.2 \\
\hline Changes in appearance, texture of skin & 60 & 55 & 33 & 30.3 & 16 & 14.7 \\
\hline Feeling bloated & 59 & 54.1 & 25 & 22.9 & 25 & 22.9 \\
\hline Backache & 70 & 64.2 & 19 & 17.4 & 20 & 18.3 \\
\hline Frequency of urination & 56 & 51.4 & 31 & 28.4 & 22 & 20.2 \\
\hline Involuntary urination during laughing or coughing & 50 & 45.9 & 25 & 22.9 & 34 & 31.2 \\
\hline \multicolumn{7}{|l|}{ Sexual } \\
\hline Change in your sexual desire & 67 & 60.9 & 23 & 20.9 & 20 & 18.2 \\
\hline Vaginal dryness during Intercourse & 51 & 46.4 & 31 & 28.2 & 28 & 25.5 \\
\hline Avoiding intimacy & 67 & 60.9 & 23 & 20.9 & 20 & 18.2 \\
\hline
\end{tabular}

*Multiple responses

Table 3. Distribution of the women by their knowledge regarding to menopause $(\mathrm{n}=150)$

\begin{tabular}{llllll}
\hline \multirow{2}{*}{ Items } & \multicolumn{2}{l}{ Satisfactory knowledge } & & \multicolumn{2}{c}{ Unsatisfactory knowledge } \\
\cline { 2 - 3 } \cline { 5 - 6 } & No & \% & & & No \\
\cline { 1 - 2 } Meaning of menopausal age & 53 & 35.3 & & 97 & 64.7 \\
Onset of menopausal age & 62 & 41.3 & & 88 & 58.7 \\
Signs and symptoms & 62 & 41.3 & & 88 & 58.7 \\
Health screening test & 54 & 36.0 & & 96 & 64.0 \\
Hormonal replacement therapy & 61 & 40.7 & & 89 & 59.3 \\
\hline
\end{tabular}

The study results answered on all research questions and demonstrated significant improvements in the severity level of the menopausal symptoms and how women dealing with it. The study sample included 150 women with more than one half of the women's their age between 45-55 years old. 78
Our results were still at the normal menopausal age. Around one third of the women had secondary education; and $20 \%$ had received high education which can improve cooperation level of the women' during the conduction of the study. 
Table 4. Distribution of the sample regarding to their practice with menopausal symptoms $(n=150)$

\begin{tabular}{|c|c|c|c|c|}
\hline \multirow{2}{*}{ Health practices* } & \multicolumn{2}{|c|}{ Proper Practices } & \multicolumn{2}{|c|}{ Improper practices } \\
\hline & No & $\%$ & No & $\%$ \\
\hline \multicolumn{5}{|l|}{ Vasomotor complains } \\
\hline Use of a fan while sleeping & 95 & 63.3 & 55 & 36.7 \\
\hline Opening all windows & 62 & 41.3 & 88 & 58.7 \\
\hline Wearing lighter-weight clothing & 61 & 40.7 & 89 & 59.3 \\
\hline Wear cotton clothes & 74 & 49.3 & 76 & 50.7 \\
\hline Avoiding drinking caffeine, hot fluids & 70 & 46.7 & 80 & 53.3 \\
\hline Avoiding spicy foods & 72 & 48.0 & 78 & 52.0 \\
\hline Soybeans, lentils and vegetables & 82 & 54.7 & 68 & 45.3 \\
\hline Drink 7 to 10 glasses of water daily & 58 & 38.7 & 92 & 61.3 \\
\hline Maintain healthy weight & 76 & 50.7 & 74 & 49.3 \\
\hline \multicolumn{5}{|l|}{ Psychosocial complains } \\
\hline Participate in a creative outlet that fosters a sense of achievement & 58 & 38.7 & 92 & 61.3 \\
\hline Participate in pleasurable activities & 61 & 40.7 & 89 & 59.3 \\
\hline Stay connected with their family and community and your friend & 77 & 51.3 & 73 & 48.7 \\
\hline \multicolumn{5}{|l|}{ Physical complains } \\
\hline Maintain the bedroom cool to prevent night sweats & 58 & 38.7 & 92 & 61.3 \\
\hline Avoid using sleeping pills & 61 & 40.7 & 99 & 59.3 \\
\hline Perform exercise daily & 20 & 13.3 & 130 & 86.7 \\
\hline Try to tack deep, slow abdominal breathing & 55 & 36.7 & 95 & 63.3 \\
\hline Maintain regular walk per day & 67 & 44.7 & 83 & 55.3 \\
\hline Avoid caffeine and alcohol at night & 73 & 48.7 & 77 & 51.3 \\
\hline $\begin{array}{l}\text { Eat } 1,000 \mathrm{mg} \text { of calcium every day to reduced risk of fracture (milk, } \\
\text { hard cheese, yoghurt or sardines) }\end{array}$ & 33 & 22.0 & 117 & 78.0 \\
\hline Take calcium and/or vitamin D tablets supplement & 58 & 38.7 & 92 & 61.3 \\
\hline Maintain of warm bath or shower at bedtime & 63 & 42.0 & 87 & 58.0 \\
\hline perform kagel exercise to strength pelvic floor muscles & 14 & 9.3 & 136 & 90.7 \\
\hline \multicolumn{5}{|l|}{ Sexual complains } \\
\hline Using a vaginal lotion or lubricant before intercourse & 43 & 28.7 & 107 & 71.3 \\
\hline
\end{tabular}

*Multiple responses

Table 5. Women distribution regarding to the total severity level of menopausal symptoms pre and posttest $(\mathrm{n}=150)$

\begin{tabular}{|c|c|c|c|c|c|c|c|c|}
\hline \multirow[b]{2}{*}{ Items $* *$} & \multicolumn{3}{|l|}{ Pre } & \multicolumn{3}{|c|}{ Post test } & \multicolumn{2}{|c|}{$P$ value } \\
\hline & $\begin{array}{l}\text { Mild } \\
\%\end{array}$ & $\begin{array}{l}\text { Moderate } \\
\%\end{array}$ & $\begin{array}{l}\text { Severe } \\
\%\end{array}$ & $\begin{array}{l}\text { Mild } \\
\%\end{array}$ & $\begin{array}{l}\text { Moderate } \\
\%\end{array}$ & $\begin{array}{l}\text { Severe } \\
\%\end{array}$ & $t$. & Sig. \\
\hline Vasomotor & 43.6 & 23.1 & 33.3 & 64.1 & 12.0 & 23.9 & 5.10 & $<.0001^{*}$ \\
\hline Psychosocial & 35.2 & 34.3 & 30.5 & 57.1 & 27.6 & 15.2 & 5.81 & $<.0001^{*}$ \\
\hline Physical & 22 & 47.7 & 30.3 & 51.4 & 28.4 & 20.2 & 6.94 & $<.0001^{*}$ \\
\hline Sexual & 46.4 & 34.5 & 19.1 & 61.8 & 26.4 & 11.8 & 4.94 & $<.0001^{*}$ \\
\hline
\end{tabular}

**Multiple responses, $(*)$ Statistically significant at $p<.0001$

According to the level of severity of menopausal symptoms, less than I used to, aching in muscle \& joints, difficulty sleepcurrent study results mentioned that, most severe symptoms reported by the women were, hot flushes, night sweats, poor memory, unhappy with their personal life, accomplishing ing, drying skin, weight gain, lack of energy, involuntary urination during laughing or coughing, increased facial hair and vaginal dryness during intercourse. This may be related 
to hormonal changes during menopausal periods. This finding go on line with the finding of several studies stated that "hot flashes" and sweating are considered as the most common symptoms reported by the women. ${ }^{[7]}$ Also Esmat and Mohamed (2013) ${ }^{[25]}$ who found that $81 \%$ of premenopausal women were experienced physical symptoms. In addition to, in the United States, ${ }^{[26]}$ the most frequently menopausal symptoms reported by the African-American women were hot flushes $(45.6 \%)$ then Hispanic $(35.4 \%)$ followed by Cau- casians (31.2\%), then Chinese (20.5\%) and Japanese (17.6\%). While results of the study done by Chim et al. (2002) ${ }^{[27]}$ indicated that "classical menopausal symptoms such as hot flushes (17.6\%), vaginal dryness $(20.7 \%)$ and night sweats $(8.9 \%)$ were less commonly reported than somatic symptoms", these results not agree with the finding of the present study and this difference may be due to genetic diversity, different cultural, diet (eating of highly phytoestrogen foods).

Table 6. Distribution of the sample regarding to their practices with menopausal complaints pre and posttest $(\mathrm{n}=150)$

\begin{tabular}{|c|c|c|c|c|c|c|c|c|c|c|}
\hline \multirow{3}{*}{$\begin{array}{l}\text { Health } \\
\text { complains }\end{array}$} & \multicolumn{4}{|c|}{ Pre } & \multicolumn{4}{|c|}{ Post test } & \multicolumn{2}{|c|}{$P$ value } \\
\hline & \multicolumn{2}{|c|}{$\begin{array}{l}\text { Proper } \\
\text { Practices }\end{array}$} & \multicolumn{2}{|c|}{$\begin{array}{l}\text { Improper } \\
\text { practices }\end{array}$} & \multicolumn{2}{|c|}{$\begin{array}{l}\text { Proper } \\
\text { Practices }\end{array}$} & \multicolumn{2}{|c|}{$\begin{array}{l}\text { Improper } \\
\text { practices }\end{array}$} & \multirow[t]{2}{*}{$t$ test } & \multirow[t]{2}{*}{ Sig. } \\
\hline & No & $\%$ & No & $\%$ & No & $\%$ & No & $\%$ & & \\
\hline Vasomotor & 46 & 30.7 & 104 & 69.3 & 114 & 76.0 & 36 & 24.0 & 10.82 & $<.0001^{*}$ \\
\hline Psychosocial & 33 & 22.0 & 117 & 78.0 & 90 & 60.0 & 60 & 40.0 & 9.55 & $<.0001^{*}$ \\
\hline Physical & 66 & 44.0 & 84 & 56.0 & 116 & 77.3 & 34 & 22.7 & 6.35 & $<.0001^{*}$ \\
\hline Sexual & 43 & 28.7 & 107 & 71.3 & 106 & 70.7 & 44 & 29.3 & 10.11 & $<.0001^{*}$ \\
\hline
\end{tabular}

$(*)$ Statistically significant at $p<.0001$

Table 7. Relation between women's knowledge and their practices $(n=150)$

\begin{tabular}{|c|c|c|c|c|c|c|c|c|}
\hline \multirow{3}{*}{ Total practices } & \multicolumn{4}{|c|}{ Total Knowledge } & \multirow{2}{*}{\multicolumn{2}{|c|}{ Total }} & \multirow{3}{*}{$\chi^{2}$} & \multirow{3}{*}{ Sig. } \\
\hline & \multicolumn{2}{|c|}{ Satisfactory } & \multicolumn{2}{|c|}{ Unsatisfactory } & & & & \\
\hline & No & $\%$ & No & $\%$ & No & $\%$ & & \\
\hline Proper & 79 & 84.9 & 14 & 15.1 & 93 & 62 & & \\
\hline Improper & 2 & 3.5 & 55 & 96.5 & 57 & 38 & 12.26 & $<.001^{*}$ \\
\hline Total & 134 & 89.3 & 16 & 10.7 & 150 & 100 & & \\
\hline
\end{tabular}

(*) Statistically significant at $p<.001$

Results of the study done by Jahanfar et al. (2006) ${ }^{[15]}$ indicated that the most common health complaints reported by the women is joint and muscle discomfort (84.3\%), then anxiety (71.4\%), followed by physical discomfort (67.2\%), then vasomotor symptoms $(67.1 \%)$. These differences in frequencies may be related to differences of culture, life style, genetics and diet. Also Gharaibeh et al. (2010) ${ }^{[18]}$ observed that hot flushes and night sweating as a vasomotor symptoms have the highest scores. Moreover Ashrafi et al. (2010) ${ }^{[28]}$ mentioned that the most common symptoms related to menopause in Iranian women are night sweats, hot flashes, joints and muscles pain. In this regard Rahman et al. $(2010)^{[29]}$ reported that sexual, bladder problems and vaginal dryness were experienced mainly by postmenopausal group of Malaysia women and it was also significant statistically when compared to other menopausal status. Present study revealed that the most prevalent psychosocial complain was reported by the women is poor memory and supported by the finding of several studies. ${ }^{[27,30]}$ These results are not agree with the finding of the study by Kalahroudi et al. $(2012)^{[31]}$ which showed that the most prevalent psychosocial complains is accomplishing less than I used to, but the most severe symptom was anxious this is contradicted with results of our study. Esmat and Mohamed (2013) ${ }^{[25]}$ found that the most of the women observed nervousness and $75 \%$ of them complain of difficulty in concentration while more than one half of them depressed and less than half of them feeling aloneness. Furthermore, Frackiewiez et al. (2008) ${ }^{[32]}$ reported that women in mid-life experience, irritability, anxiety, mode changes, sleeplessness and unhappiness.

Regarding physical complains, our study showed that most severe symptoms were aching in muscle \& joints, difficulty sleeping, drying skin, lack of energy, weight gain, involuntary urination, this results go on line with the study done by Askari et al. (2008) ${ }^{[33]}$ who stated that the most complain is lack of energy while aching muscles and joints pain 
are the most severe symptom but somatic and psychological symptoms are not related to menopausal status because these symptoms are multi-factorial, rather than due to hormonal imbalance and middle-aged women usually experience these symptoms due to health problems related with aging. In addition Nisar and Ahmed (2009) ${ }^{[26]}$ stated that the frequency of physical symptoms was $99 \%$ compared to sexual symptoms $66 \%$. Other study was done by Greenblum et al. $(2012)^{[6]}$ indicated that the most common symptom experienced by the women was hot flashes $(73.2 \%)$, then fatigue $(58.0 \%)$, followed by sleep disturbances $(56.3 \%)$, then anxiety $(53.6 \%)$, irritability $(51.8 \%)$, weight gain $(51.8 \%)$, vaginal dryness $(48.2 \%)$, and urinary incontinence $(32.1 \%)$, Also Citra et al. $(2008)^{[34]}$ mentioned that more than half of menopausal women had muscle and joint pain.

A study done by Esmat, and Mohamed (2013) ${ }^{[25]}$ indicated that hot flashes, muscle or joint pain reported by the majority of women and more than three quarters complained from headache, in addition about three quarters of them had night sweat while more than two third complained from sleep disturbance. This finding was in contradict with the study done by Utain, (2007) ${ }^{[35]}$ they observed that more one quarter of women complained from physical problem. This finding was in line with Nelson, $(2008)^{[36]}$ who mentioned that more than half of women complained from physical problems and $40 \%$ to $60 \%$ from them had sleep disturbance, night sweat and hot flashes. Result of current study reach agreement with Gohar et al. (2009) ${ }^{[7]}$ who found that hot flushes and tiredness are the most symptoms experienced by the Egyptian menopausal women. Also Obermeyer et al. (2009) ${ }^{[37]}$ found that the most common symptoms among menopausal women were hot flushes, joint pain, sweating and palpitation. This may be due to alteration in estrogen level which causing sweating and hot flushing.

Regarding sexual domains the results of the present study indicated that only one quadrant of menopausal women complain with severe vaginal dryness during intercourse and around two third complain with mild change sexual desired. This result was not agreement with women in Korea, a change in sexual desire is the most common symptom and it is severe in $27 \%$ of cases. ${ }^{[30]}$ In addition to study done by Esmat, and Mohamed (2013) ${ }^{[25]}$ found that decrease sexual desire, vaginal dryness during intercourse experienced by around two thirds of menopausal women and less than three quarters from them complained from dyspareunia. These findings agree with the results of the study done by Seif et al. $(2008)^{[38]}$ they reported that, loss of libido and vaginal dryness are the most common complained of Egyptian women during menopausal period. This results reinforced by Dennerstein et al. (2008) ${ }^{[39]}$ and Nicolosi et al. (2009) ${ }^{[40]}$ they

Published by Sciedu Press observed that dyspareunia and absent or decrease of sexual desire are experienced by most Egyptian menopausal women. Also Gharaibeh et al. (2010) ${ }^{[18]}$ stated that the prevalence of "change in sexual desire" was approximately $30.7 \%$.

Regarding to knowledge of the women, the results of the current study indicated that above half of the women had unsatisfactory knowledge about menopausal period related to meaning, onset, signs and symptoms, screening and hormonal therapy, this may be related to lack of awareness about menopausal age, and hormonal replacement therapy. This results go in line with Esmat, and Mohamed (2013) ${ }^{[25]}$ who found that more than two third of women had unsatisfactory knowledge; related to meaning and types of hormonal therapy. In addition Sallam et al. $(2008)^{[41]}$ mentioned that women had low information regarding to menopause age.

Results of the present study pre-program, identified more than two third of the woman were improper practice with common health complains associated with menopausal age. This reflect the women needs for increasing their awareness regarding aspects of health promotion during this age. These results go in line with Esmat et al. (2013) ${ }^{[25]}$ who mentioned that improper practices to deal with physical, sexual, and psychological health complains observed among premenopausal women. While the results of the study done by Seif et al. (2008) ${ }^{[38]}$ mentioned that proper practices to dealing with physical health complains during menopausal period observed among more than half of menopausal women, and unsuccessful to dealing with psychological and sexual health complains. At the post program follow up, study results indicated to reduction in number of the women complains from severe menopausal symptoms with statistical significant differences $(P<.000)$ between pre and posttest. This may be due to success of the intervention, which is positively reflected on knowledge and practices improvement for how to deal with menopausal symptoms. In addition at posttest it observed that more than two third of the women have proper practice of vasomotor, physical and sexual health complain as compared to around one third at pretest with highly statistical significant differences $(P<.000)$ between pre and posttest. These results confirmed by the finding of the study done by Esmat et al. (2013), ${ }^{[25]}$ Seif et al. $(2008)^{[38]}$ and Clark (2008). ${ }^{[42]}$ They showed statistically significant relationship between knowledge of the women and their practices with health complaints accompanying the menopausal period.

\section{CONCLUSION AND RECOMMENDATION}

According to results of the current study it can be concluded that, the most severe symptoms experienced by the women are, hot flushes, poor memory, aching in muscle or joints, 
difficulty in sleeping, and vaginal dryness. More than one half of menopausal women had unsatisfactory knowledge regarding menopause and large percent of them had improper practices with common health complains associated with menopausal age. There was a statistically significant relationship between knowledge of the women and the reduction of the severity level of menopausal symptoms, and also between women's knowledge and their practices with common

\section{REFERENCES}

[1] Bernis C, Reher DS. Environmental contexts of menopause in Spain: comparative results from recent research. Menopause. 2007; 14(4) 777-787. PMid:17679148 http://dx.doi.org/10.1097/gme.0 b013e31803020ff

[2] Williams RE, Levineb BK, Kalilani LB, et al. Menopause-specific questionnaire assessment in US population-based study shows negative impact on health-related quality of life. Maturities. 2009; 62(2): 153-159. PMid:19157732 http://dx.doi .org/10.1016/j . mat uritas.2008.12.006

[3] Lewis V. Under treatment of menopausal symptoms and novel options for comprehensive management. Cur Med Res Opin. 2009; 25 2689-2698. PMid:19775194 http://dx.doi .org/10.1185/030 07990903240519

[4] Thurston R, Joffe H. Vasomotor symptoms and menopause: findings from the Study of Women's Health Across the Nation. Obstetric Gynecology Clin North Am. 2011; 38: 489-501. PMid:21961716 http://dx.doi.org/10.1016/j.ogc.2011.05.006

[5] Ford K, Sowers M, Crutchfield M, et al. Longitudinal study of the predictors of prevalence and severity of symptoms commonly associated with menopause. Menopause. 2011; 12: 308-317. http: //dx.doi.org/10.1097/01.GME.0000163869.89878.D9

[6] Greenblum CA, Meredeth A, Rowe Neff DF, et al. Midlife women: symptoms associated with menopausal transition and early post menopause and quality of life. Journal of the North American Menopause Society. 2012; 20(1).

[7] Gohar I. Design, implementation and evaluation of reproductive health informational guide for postmenopausal women. MD thesis, Alexandria University, Faculty of Nursing. 2009.

[8] Heinemann K, Ruebig A, Potthoff P, et al. The Menopause Rating Scale (MRS) scale: A methodological review. Health Qual Life Outcomes. 2004; 2: 45. PMid:15345062 http://dx.doi .org/10.11 86/1477-7525-2-45

[9] Mishra G, Kuh D. Perceived change in quality of life during the menopause. Social Sci Med. 2006; 62: 93-102. PMid:15990213 http://dx.doi.org/10.1016/j. socscimed.2005.05.015

[10] Sallam H, Galal AF, Rashed A. Menopause in Egypt: past and present perspectives, The Suzanne Mubarak Regional Center for Women's Health and Development, Egypt. 2006; 9(6): 421-429.

[11] Lund K. Menopause and the menopausal transition. The medical clinics of North America. 2008; 92(11): 1253-1271. PMid:18721661 http://dx.doi.org/10.1016/j.mcna.2008.04.009

[12] Ganger K, Key F. Individualizing HRT. Practitioner. 2007; 237(1525): 358.

[13] Lowdermilk DL, Perry S, Bobak I. Maternity and women's Health Care. 7th ed. Landon: Mosby Company. 2009. 128-142 p. menopausal health complains. Based on these findings it is recommended to, health care providers need to play essential role in assessing women's needs and increase women awareness through implementing proper health educational session about the menopausal age and how to deal with common health complains associated with menopausal age.

\section{CONFLicts OF InTEREST Disclosure}

The authors declare that there is no conflict of interest.
[14] Lewisa JE, Hilditcha JR, Wongb CJ. Further psychometric property development of the Menopause-Specific Quality of Life questionnaire and development of a modified version, MENQOL-Intervention questionnaire. Maturities. 2005; 50: 209-221. PMid:15734602 http: //dx.doi.org/10.1016/j.maturitas.2004.06.015

[15] Jahanfar SH, Abdul Rahim BA, Shah Reza BK, et al. Age of Menopause and Menopausal Symptoms Among Malaysian Women Who Referred to Health Clinic in Malaysia. Shiraz E-Medical Journal. 2006; 7: 1-9.

[16] Waidyasekera H, Wijewardena K, Lindmark G, et al. Menopausal symptoms and quality of life during the menopausal transition in Sri Lankan women. Menopause. 2009; 16: 164-170. PMid:18703984 http://dx.doi.org/10.1097/gme.0b013e31817a8abd

[17] McKinney ES, Ashwill JW, Murray SS, et al. Maternal-Child Nursing. St. Louis: Elsevier Science Health Science Division. 2012.

[18] Gharaibeh M, Al-Obeisat S, Hattab J. Severity of menopausal symptoms of Jordanian women. Climacteric. 2010; 13(4): 385394. PMid:19731118 http://dx.doi .org/10.3109/136971309 03050009

[19] Avis NE, Assmann SF, Kravitz HM. Quality of life in diverse groups of midlife women: assessing the influence of menopause, health status and psychosocial and demographic factors. Quality Life Res. 2004; 13: 933-946. http://dx.doi.org/10.1023/B: QURE.0000025582.91310.9f

[20] Cooper R, Kuh D, Hardy R, et al. Objectively measured physical capability levels and mortality: Systematic review and meta-analysis. BMJ. 2010; 341: 4467. PMid:20829298 http://dx.doi.org/10. $1136 / \mathrm{bmj} . \mathrm{c} 4467$

[21] Studenski S, Perera S, Patel K. Gait speed and survival in older adults. JAMA. 2011; 305: 50-58. PMid:21205966 http://dx. doi .org/1 $0.1001 /$ jama. 2010.1923

[22] Cardinal and Stritch University Library. Dorothea Orem 1914- Self-care Framework. 2011. Available from: http://library.stritch.edu/research/subjects/he alth/nursingTheorists/orem.html

[23] Sitzman KL, Eichelberger LW. Understanding the Works of Nurse Theorists: A Creative Beginning (2nd ed.). Sudbury, MA: Jones and Barlett Learning. 2011; 96 p.

[24] Ricci SS. Essentials of maternity, newborn and women's health nursing, nursing management during the postpartum, 2nd. Lippincott Williams \& Wilkins. 2009; 434-435 p.

[25] Esmat H, Mohamed H. Menopausal Transition and Its Effect on Women's Health. Journal of American Science. 2013; 9(1).

[26] Nisar N, Ahmed SN. Frequency of menopausal symptoms and their impact on the Quality of life of women: A hospital based survey. J. Pak Med Association. 2009; 59(11): 752-756. PMid:20361673 
[27] Chim H, Tan BH, Ang CC, et al. The prevalence of menopausal symptoms in a community in Singapore. 41Maturitas. 2002; 4: 275-82. http://dx.doi.org/10.1016/S0378-5122(01) 00299-7

[28] Ashrafi M, Ashtiani SK, Malekzadeh F, et al. Symptoms of natural menopause among Iranian women living in Tehran, Iran. Int $\mathbf{J}$ of Reproductive Medicine. 2010; 8(1): 29-32.

[29] Rahman SA, Zainudin SR, Kar Mun VL. Assessment of menopausal symptoms using modified Menopause Rating Scale (MRS) among middle age women in Kuching, Sarawak, Malaysia. Asia Pacific Family Medicine. 2010; 9: 5. PMid:20175928 http://dx.doi.o $\mathrm{rg} / 10.1186 / 1447-056 \mathrm{X}-9-5$

[30] Lee MS, Kim JH, Park MS, et al. Factors influencing the severity of menopause symptoms in Korean post-menopausal women. J Korean Med Sci. 2010; 5: 758-65. PMid:20436714 http://dx.doi.org $/ 10.3346 / \mathrm{jkms} .2010 .25 .5 .758$

[31] Kalahroudi MA, Mahboubeh T, Sadat Z, et al. Prevalence and Severity of Menopausal Symptoms and Related Factors Among Women 40-60 Years in Kashan, Iran. Nurs Midwifery Stud. 2012; 1(2): 88-93. http://dx.doi.org/10.5812/nms. 8358

[32] Frackiewicz EJ, Cutler NR. Women's health care during the per menopause. Journal of the American Pharmacological Association. 2008; 40(6): 124-130.

[33] Askari F, Basiri Moghadam K, Basiri Moghadam M, et al. Age of Natural Menopause and the Comparision of Incidence of Its Early Complications in Menopause Transition stages in Women From Galabad City. Of ghee Danish. 2008.
[34] Citra NM, Chong S, Su LL, et al. Care of women in Menopause, Ann Acad Med Singapore. 2008; 37(3): 215-223.

[35] Utian WH. Psychosocial and socioeconomic burden of vasomotor symptoms in menopause. Health and quality of life outcome. 2007; 3(47): 1-10.

[36] Nelson D. Menopause. Lancet. 2008; 371(3): 760-770. http: //dx.doi.org/10.1016/s0140-6736(08)60346-3

[37] Obeermeyer CM, Schulein M, Hajji N, et al. Menopause in morocco: Symptomatology and medical management. Maturities. 2009; 41(2): 87-95. http://dx.doi.org/10.1016/S0378-5122(01) 00289 $-4$

[38] Sief NY, Rayhab SO, Abd Elaziz NA, et al. Women's practices with menopause "Instructional Guidelines for better coping" Community Health Nursing. Faculties of Nursing. Ain Shams University and Cairo University. 2008. 1-14 p.

[39] Dennerstein L. Well-being, symptoms and the menopausal transition Maturities. 2008; 23: 147-157. http://dx.doi.org/10.1016/0 378-5122(95) 00970-1

[40] Nicolosi A, Laumann E, Glasser D, et al. Sexual behavior and sexual dysfunction after age 40. Urology. 2009; 4(8): 991-997.

[41] Sallam H, Galal A, Rashed A. Menopause in Egypt: past and present perspectives. Climacteric. 2008; 9(1): 211-429.

[42] Clark M. Community Health Nursing "Advocacy for population Health", 5th ed. Pearson prentice Hall, New Jersey: 2008. 423-461 p. 